\title{
Influence of spray liquid acidity on effectiveness of some growth regulators in spring barley crops
}

\author{
Wpływ kwasowości cieczy opryskowej na skuteczność działania \\ wybranych retardantów wzrostu stosowanych w uprawie jęczmienia jarego
}

\author{
Wojciech Miziniak
}

\section{Summary}

The field experiments with spring barley cultivar Justina were conducted in 2010-2011. The tested products (Regalis 10 WG, Modus 250 EC, Antywylegacz Płynny 675 SL, Cerone $480 \mathrm{SL}$ ) were applied on spring barley at the stage of BBCH 32 . The height reduction of spring barley was dependent on the active substance of growth regulators and weather conditions, and it was $0-5.9 \%$ (2010) and 1.6-9.8\% (2011), respectively. Higher effectiveness of shortening stems of spring barley was obtained after the use of Cerone $480 \mathrm{SL}$ at the dose of $0.75 \mathrm{l} / \mathrm{ha}$. In two years of investigation lack of statistic differences between growth retardants prohexadione- $\mathrm{Ca}$, chloromequat chloride and ethephone regardless of $\mathrm{pH}$ spray liquid. Lower $\mathrm{pH}$ of spray liquid containing trinexapak ethyl showed better efficacy (shorter stems and lower lodging) in comparison to plots on which trinexapak ethyl on neutral pH was used. The examined growth regulators did not cause any injury to spring barley cultivar Justina. Acidity of spray liquid containing growth regulators increased the yield of spring barley in comparison to untreated plots and plots on which growth regulators were used in neutral $\mathrm{pH}$.

Key words: spring barley, growth regulators, prohexadione-Ca, chloromeqat chloride, trinexapak ethyl, ethephone, adjuvant

\section{Streszczenie}

Doświadczenia polowe prowadzono w latach 2010-2011, w uprawie jęczmienia jarego odmiany Justina. Badane retardanty wzrostu (Regalis 10 WG, Modus 250 EC, Antywylegacz Płynny 675 SL, Cerone 480 SL) zastosowano w fazie strzelania w źdźbło jęczmienia jarego (BBCH 32). Efektywność działania badanych preparatów uzależniona była od substancji czynnej oraz od warunków atmosferycznych i wynosiła, w zależności od roku badań, od 0-5,9\% (2010) do 1,6-9,8\% (2011) skrócenia źdźbeł. W obydwu latach badań największe skrócenie długości źdźbeł w porównaniu do kontroli uzyskano po zastosowaniu retardanta Cerone 480 SL w dawce $0,75 \mathrm{l} / \mathrm{ha}$. W dwuletnich badaniach nie stwierdzono istotnych różnic pomiędzy wariantami badań, w których stosowano następujące retardanty wzrostu: proheksadion wapnia, chlorek chloromekwatu oraz etefon niezależnie od pH cieczy opryskowej. W wyniku obniżenia pH cieczy opryskowej zawierającej trineksapak etylu stwierdzono lepsze działanie retardacyjne trineksapaku etylu (redukcja wysokości roślin, obniżenie wylegania) w porównaniu do wariantu badań, w którym stosowano preparat o odczynie roztworu zbliżonym do obojętnego. Badane preparaty nie wykazywały fitotoksycznego wpływu na rośliny jęczmienia jarego odmiany Justina. Obniżenie pH cieczy opryskowej zawierającej retardanty wzrostu przyczyniło się do wzrostu plonowania jęczmienia jarego w porównaniu do plonowania jęczmienia na obiektach bez zabiegu oraz do poletek, na których nie stosowano obniżenia pH cieczy opryskowej.

Słowa kluczowe: jęczmień jary, retardanty wzrostu, proheksadion wapnia, chlorek chloromekwatu, trineksapak etylu, etefon, adiuwant

w.miziniak@iorpib.poznan.pl 


\section{Wstęp / Introduction}

Wyleganie roślin stanowi poważny problem w uprawie zbóż. Intensyfikacja produkcji rolniczej przyczynia się do wzrostu zagrożenia tym zjawiskiem. Jeżeli wystapi ono we wczesnych fazach rozwojowych, to może być powodem znacznych strat w plonie ziarna. Obniżenie plonowania wynika głównie z powodu zakłócenia wzrostu i rozwoju roślin, zmniejszenia natężenia fotosyntezy oraz pobierania składników pokarmowych z gleby. Zjawisko to powoduje ponadto wzrost kosztów związanych ze zbiorem, wydłuża czas konieczny do jego przeprowadzenia oraz obniża jakość ziarna (Sterry i wsp. 1980; Kelbert i wsp. 2004; Tripathi i wsp. 2004).

W celu zmniejszenia ryzyka wylegania, w intensywnej uprawie zbóż powszechnie stosowane są egzogenne związki ograniczające wzrost i rozwój roślin - retardanty wzrostu. Jednak skuteczność ich działania, podobnie jak innych środków ochrony roślin, uzależniona jest między innymi od warunków klimatycznych. Ograniczenie niekorzystnego wpływu tych warunków na działanie herbicydów dolistnych można uzyskać przez stosowanie ich $\mathrm{z}$ adiuwantami. Adiuwanty mineralne stanowią grupę związków, które w sposób bezpośredni i pośredni polepszają działanie herbicydów nalistnych (np. siarczan amonowy, azotan amonowy, mocznik). Główną ich funkcją jest: zmiana odczynu cieczy roboczej, zwiększenie rozpuszczalności substancji czynnej herbicydu, zmiana jej charakteru chemicznego, korzystniejsze rozmieszczenie substancji czynnej w depozycie, spowolnienie wytrącania osadu i jego krystalizacji, wzrost przepuszczalności błony komórkowej, a zarazem zwiększenie transportu substancji czynnej. Jak wykazały badania, rozpuszczalność niektórych środków ochrony roślin, w tym herbicydów sulfonylomocznikowych, uzależniona jest od pH cieczy użytkowej. Woźnica i wsp. (2003) wykazali, że wzrost pH cieczy powyżej 7,0 przez dodanie odpowiedniego adiuwanta spowodował podwojenie efektywności chwastobójczej quinkloraku. Podobne zależności uzyskali także Green i Cahill (2003) oraz Szeleźniak (2005), stosując odpowiednio nikosulfuron i tralkoksydym $\mathrm{z}$ buforami $\mathrm{pH}$.

Celem badań było określenie wpływu obniżenia $\mathrm{pH}$ cieczy opryskowej na skuteczność działania wybranych retardantów wzrostu w uprawie jęczmienia jarego.

\section{Materiały i metody / Materials and methods}

Doświadczenia polowe przeprowadzono w latach 2010-2011, w jęczmieniu jarym odmiany Justina, w układzie statystycznym losowanych bloków. Retardanty wzrostu testowano w czterech powtórzeniach na poletkach o powierzchni $12 \mathrm{~m}^{2}$. Obiektami badań były następujące substancje czynne: proheksadion wapnia (Regalis $10 \mathrm{WG}$ ); trineksapak etylu (Moddus 250 EC); chlorek chloromekwatu - CCC (Antywylegacz Płynny 675 SL) i etefon (Cerone 480 SL). Stosowano je używając wody o odczynie obojętnym oraz po zakwaszeniu cieczy opryskowych kwasem cytrynowym (1 g kwasu cytrynowego/1 litr wody). Aplikację badanych środków przeprowadzono w fazie strzelania w źdźbło jęczmienia jarego (BBCH 32).
Zabiegi wykonano opryskiwaczem rowerowym typu Victoria, wyposażonym w rozpylacze TEEJET 11002 VP, o wydatku cieczy opryskowej 2001 na ha. Ciśnienie robocze wynosiło $0,25 \mathrm{MPa}$.

Pomiaru wysokości roślin dokonano w fazie dojrzałości woskowej ziarniaków (BBCH 83), mierząc po 25 losowo wybranych roślin z każdego poletka. Określano długość źdźbła od powierzchni gleby do podstawy kłosa. Wyleganie oceniano wizualnie za pomocą skali procentowej, w której przyjęto: 0\% - brak wylegania (wszystkie rośliny na całej powierzchni poletek były wyprostowane), 100\%całkowite wyleganie (wszystkie rośliny na całej powierzchni poletek ułożone poziomo). W okresie wegetacji roślin przeprowadzano systematyczne, wizualne oceny wrażliwości jęczmienia jarego na zastosowane preparaty. W trakcie wegetacji roślin zastosowano nawożenie mineralne na poziomie $100 \mathrm{~kg} \mathrm{~N}, 30 \mathrm{~kg} \mathrm{P}_{2} \mathrm{O}_{5}, 60 \mathrm{~kg}$ $\mathrm{K}_{2} \mathrm{O} /$ ha oraz standardową ochronę przeciwko chorobom i szkodnikom. Próby roślin do określenia struktury plonu pobrano z powierzchni $1 \mathrm{~m}^{2}$.

Analizie statystycznej poddano dane dotyczące: obsady, wysokości roślin, wylegania, liczby ziaren w kłosie, plonów ziarna oraz masy tysiąca ziaren. Wyniki testu Fishera oceniano na poziomie istotności 1 i $5 \%$. Po stwierdzeniu istotnych różnic dokonano szczegółowego porównania średnich za pomocą testu t-Studenta, wyznaczając najmniejszą istotną różnicę na poziomie istotności 5\%.

\section{Wyniki i dyskusja / Results and discussion}

Woda zastosowana do sporządzenia roztworów użytkowych posiadała odczyn obojętny $(7,48)$. Rozpuszczenie w wodzie proheksadionu wapnia i chlorku chloromekwatu nie miało wpływu na odczyn $\mathrm{pH}$ cieczy użytkowej. Dla porównania roztwór trineksapaku etylu charakteryzował się odczynem lekko kwaśnym, natomiast najniższe wartości pH uzyskano w cieczy użytkowej zawierającej etefon $(2,20)$. Dodatek kwasu cytrynowego do cieczy opryskowej zawierającej roztwory retardantów wzrostu (proheksadion wapnia, trineksapak etylu i chlorek chloromekwatu) W większości wariantów badań spowodował obniżenie pH cieczy opryskowej (tab. 1). Rozpuszczenie kwasu cytrynowego w cieczy użytkowej zawierającej etefon nie wpłynęło na zmianę pH cieczy, gdyż sam roztwór retardanta wzrostu miał odczyn kwaśny (tab. 1).

Ważnym czynnikiem determinującym działanie retardantów jest rozkład opadów w okresie wegetacji roślin. W kwietniu i maju 2010 roku wystapiły wyższe opady deszczu niż w analogicznym terminie 2011 roku i wyniosły odpowiednio 187,0 i $65,1 \mathrm{~mm}$. Skuteczność działania retardantów również $\mathrm{w}$ dużej mierze uzależniona jest od temperatury powietrza. W okresie 14 dni od aplikacji badanych preparatów w 2010 roku odnotowano niższą średnią dobową temperaturę powietrza, niż w analizowanym okresie 2011 roku, która wyniosła odpowiednio 16,2 i $19,2^{\circ} \mathrm{C}$. W związku ze zmiennymi warunkami atmosferycznymi w obydwu latach badań uzyskano zróżnicowane działanie retardacyjne badanych preparatów. Podobne spostrzeżenia dotyczące wpływu warunków 
Tabela 1. Wpływ kwasu cytrynowego na pH cieczy użytkowych zawierających retardanty wzrostu

Table 1. Influence of citric acid on spray liquid $\mathrm{pH}$ containing selected growth regulators

\begin{tabular}{l|c|c}
\multicolumn{1}{c|}{$\begin{array}{c}\text { Obiekt } \\
\text { Treatment }\end{array}$} & $\begin{array}{c}\text { Dawka } \\
\text { Dose } \\
{[1, \mathrm{~kg} / \mathrm{ha}]}\end{array}$ & $\mathrm{pH}$ \\
\hline Woda - Water & - & 7,48 \\
\hline $\begin{array}{l}\text { Woda + Kwas cytrynowy } \\
\text { Water + citric acid }\end{array}$ & 0,2 & 3,70 \\
\hline $\begin{array}{l}\text { Proheksadion wapnia } \\
\text { Prohexadione-Ca }\end{array}$ & 0,5 & 7,19 \\
\hline $\begin{array}{l}\text { Proheksadion wapnia + kwas cytrynowy } \\
\text { Prohexadione-Ca + citric acid }\end{array}$ & $0,5+0,2$ & 3,81 \\
\hline $\begin{array}{l}\text { Trineksapak etylu } \\
\text { Trinexapak ethyl }\end{array}$ & 0,4 & 6,71 \\
\hline $\begin{array}{l}\text { Trineksapak etylu + kwas cytrynowy } \\
\text { Trinexapak ethyl + citric acid }\end{array}$ & $0,4+0,2$ & 3,53 \\
\hline $\begin{array}{l}\text { Chlorek chloromekwatu } \\
\text { Chloromequat chloride }\end{array}$ & 2,0 & 7,10 \\
\hline $\begin{array}{l}\text { Chlorek chloromekwatu }+ \text { kwas cytrynowy } \\
\text { Chloromequat chloride + citric acid }\end{array}$ & $2,0+0,2$ & 3,75 \\
\hline $\begin{array}{l}\text { Etefon } \\
\text { Ethephone }\end{array}$ & 0,75 & 2,20 \\
\hline $\begin{array}{l}\text { Etefon + kwas cytrynowy } \\
\text { Ethephone + citric acid }\end{array}$ & $0,75+0,2$ & 2,11
\end{tabular}

Tabela 2. Wpływ kwasowości cieczy opryskowej na efektywność działania wybranych retardantów wzrostu Table 2. Influence of spray liquid acidity on the effectiveness of some growth regulators

\begin{tabular}{|c|c|c|c|c|c|c|c|}
\hline \multirow[t]{2}{*}{$\begin{array}{l}\text { Obiekt } \\
\text { Treatment }\end{array}$} & \multirow{2}{*}{$\begin{array}{c}\text { Dawka } \\
\text { Dose } \\
{[1, \mathrm{~kg} / \mathrm{ha}]}\end{array}$} & \multicolumn{2}{|c|}{$\begin{array}{c}\text { Fitotoksyczność } \\
\text { Phytotoxicity } \\
{[\%]} \\
\end{array}$} & \multicolumn{2}{|c|}{$\begin{array}{l}\text { Wysokość roślin } \\
\text { Stem height } \\
{[\mathrm{cm}]}\end{array}$} & \multicolumn{2}{|c|}{$\begin{array}{c}\text { Wyleganie } \\
\text { Crop lodging } \\
{[\%]}\end{array}$} \\
\hline & & 2010 & 2011 & 2010 & 2011 & 2010 & 2011 \\
\hline Kontrola - Untreated & - & 0 & 0 & $73,0 \mathrm{abc}$ & $54,8 \mathrm{a}$ & $40,1 \mathrm{a}$ & 0 \\
\hline $\begin{array}{l}\text { Proheksadion wapnia } \\
\text { Prohexadione-Ca }\end{array}$ & 0,5 & 0 & 0 & $69,9 \mathrm{bcd}$ & $51,4 \mathrm{ab}$ & $38,9 \mathrm{a}$ & 0 \\
\hline $\begin{array}{l}\text { Proheksadion wapnia }+ \text { kwas } \\
\text { cytrynowy } \\
\text { Prohexadione-Ca }+ \text { citric acid } \\
\end{array}$ & $0,5+0,2$ & 0 & 0 & $74,5 \mathrm{ab}$ & $49,7 \mathrm{~b}$ & $44,0 \mathrm{a}$ & 0 \\
\hline $\begin{array}{l}\text { Trineksapak etylu } \\
\text { Trinexapak ethyl }\end{array}$ & 0,4 & 0 & 0 & $75,7 \mathrm{a}$ & $48,5 \mathrm{~cd}$ & $39,9 \mathrm{a}$ & 0 \\
\hline $\begin{array}{l}\text { Trineksapak etylu + kwas cytrynowy } \\
\text { Trinexapak ethyl + citric acid }\end{array}$ & $0,4+0,2$ & 0 & 0 & $65,5 \mathrm{~d}$ & $48,4 \mathrm{~cd}$ & $18,5 \mathrm{~b}$ & 0 \\
\hline $\begin{array}{l}\text { Chlorek chloromekwatu } \\
\text { Chloromequat chloride }\end{array}$ & 2,0 & 0 & 0 & $69,7 \mathrm{bcd}$ & $53,9 \mathrm{ab}$ & $42,7 \mathrm{a}$ & 0 \\
\hline $\begin{array}{l}\text { Chlorek chloromekwatu + kwas } \\
\text { cytrynowy } \\
\text { Chloromequat chloride }+ \text { citric acid }\end{array}$ & $2,0+0,2$ & 0 & 0 & $72,6 a b c$ & $52,2 \mathrm{ab}$ & $42,5 \mathrm{a}$ & 0 \\
\hline $\begin{array}{l}\text { Etefon } \\
\text { Ethephone }\end{array}$ & 0,75 & 0 & 0 & $68,7 \mathrm{~cd}$ & $49,4 \mathrm{bc}$ & $41,7 \mathrm{a}$ & 0 \\
\hline $\begin{array}{l}\text { Etefon }+ \text { kwas cytrynowy } \\
\text { Ethephone }+ \text { citric acid }\end{array}$ & $0,75+0,2$ & 0 & 0 & $69,7 \mathrm{bcd}$ & $51,4 \mathrm{ab}$ & $39,5 \mathrm{a}$ & 0 \\
\hline $\operatorname{NIR}(0,05)-\operatorname{LSD}(0.05)$ & & - & - & 5,38 & 4,74 & 9,23 & - \\
\hline
\end{tabular}

Wartości w kolumnach oznaczone tą samą literą nie różnią się istotnie

Values in columns marked with the same letters do not differ significantly 
Tabela 3. Wpływ kwasowości cieczy opryskowej zawierającej retardanty wzrostu na wybrane parametry plonu Table 3. Influence of spray liquid acidity on some yield parameters

\begin{tabular}{|c|c|c|c|c|c|c|c|c|c|}
\hline \multirow[t]{2}{*}{$\begin{array}{l}\text { Obiekt } \\
\text { Treatment }\end{array}$} & \multirow[t]{2}{*}{$\begin{array}{c}\text { Dawka } \\
\text { Dose } \\
{[1, \mathrm{~kg} / \mathrm{ha}]}\end{array}$} & \multicolumn{2}{|c|}{$\begin{array}{l}\text { Obsada źdźbeł } \\
{\left[\mathrm{szt} . / \mathrm{m}^{2}\right]} \\
\text { Stem density } \\
{\left[\mathrm{pcs} / \mathrm{m}^{2}\right]}\end{array}$} & \multicolumn{2}{|c|}{$\begin{array}{c}\text { MTZ } \\
1000 \text { grain weight } \\
{[\mathrm{g}]}\end{array}$} & \multicolumn{2}{|c|}{$\begin{array}{c}\text { Liczba } \\
\text { ziaren } \mathrm{w} \text { kłosie } \\
\text { [szt.] } \\
\text { No grain per one } \\
\text { earn } \\
\text { [pcs] }\end{array}$} & \multicolumn{2}{|c|}{$\begin{array}{l}\text { Plon ziarna } \\
\text { Grain yield } \\
\text { [t/ha] }\end{array}$} \\
\hline & & 2010 & 2011 & 2010 & 2011 & 2010 & 2011 & 2010 & 2011 \\
\hline Kontrola - Untreated & - & 751,0 & 522,0 & $40,02 \mathrm{abc}$ & $51,49 \mathrm{ab}$ & 19,0 & 20,3 & 5,71 & $5,21 \mathrm{e}$ \\
\hline $\begin{array}{l}\text { Proheksadion wapnia } \\
\text { Prohexadione-Ca }\end{array}$ & 0,5 & 798,5 & 577,0 & $40,14 \mathrm{abc}$ & $49,82 \mathrm{~b}$ & 19,5 & 21,1 & 6,20 & 5,73 bcde \\
\hline $\begin{array}{l}\text { Proheksadion wapnia }+ \text { kwas } \\
\text { cytrynowy } \\
\text { Prohexadione-Ca + citric acid }\end{array}$ & $0,5+0,2$ & 748,0 & 553,5 & $41,23 \mathrm{ab}$ & $52,74 \mathrm{a}$ & 19,2 & 20,7 & 5,93 & $6,04 \mathrm{abcd}$ \\
\hline $\begin{array}{l}\text { Trineksapak etylu } \\
\text { Trinexapak ethyl } \\
\end{array}$ & 0,4 & 746,5 & 542,5 & $40,48 \mathrm{ab}$ & $51,55 \mathrm{ab}$ & 19,3 & 20,5 & 5,81 & $5,50 \mathrm{de}$ \\
\hline $\begin{array}{l}\text { Trineksapak etylu + kwas cytrynowy } \\
\text { Trinexapak ethyl + citric acid }\end{array}$ & $0,4+0,2$ & 811,0 & 574,5 & $42,10 \mathrm{a}$ & $51,11 \mathrm{ab}$ & 18,0 & 20,8 & 6,25 & $6,25 \mathrm{abc}$ \\
\hline $\begin{array}{l}\text { Chlorek chloromekwatu } \\
\text { Chloromequat chloride }\end{array}$ & 2,0 & 779,0 & 555,5 & $41,38 \mathrm{ab}$ & $51,61 \mathrm{ab}$ & 18,5 & 20,8 & 5,96 & 5,63 cde \\
\hline $\begin{array}{l}\text { Chlorek chloromekwatu + kwas } \\
\text { cytrynowy } \\
\text { Chloromequat chloride }+ \text { citric acid }\end{array}$ & $2,0+0,2$ & 737,5 & 557,5 & $38,88 \mathrm{bc}$ & $52,02 \mathrm{a}$ & 19,7 & 20,6 & 5,64 & $6,32 \mathrm{ab}$ \\
\hline $\begin{array}{l}\text { Etefon } \\
\text { Ethephone }\end{array}$ & 0,75 & 808,5 & 579,5 & $38,13 \mathrm{c}$ & $51,41 \mathrm{ab}$ & 18,7 & 20,5 & 5,77 & $5,93 \mathrm{abcd}$ \\
\hline $\begin{array}{l}\text { Etefon }+ \text { kwas cytrynowy } \\
\text { Ethephone }+ \text { citric acid }\end{array}$ & $0,75+0,2$ & 764,0 & 593,0 & $39,07 \mathrm{bc}$ & $52,21 \mathrm{a}$ & 18,7 & 20,0 & 5,60 & $6,51 \mathrm{a}$ \\
\hline $\operatorname{NIR}(0,05)-\operatorname{LSD}(0.05)$ & - & r.n. & r.n. & 2,541 & 2,007 & r.n. & r.n. & r.n. & 0,680 \\
\hline
\end{tabular}

r.n. - różnica nieistotna - not significant difference

Wartości w kolumnach oznaczone tą samą literą nie różnią się istotnie

Values in columns marked with the same letters do not differ significantly

atmosferycznych (temperatury i opadów) na działanie retardantów wzrostu odnotowali Toboła i Muśnicki (1998) oraz Łęgowiak i Wysmułek (2000).

W przypadku zastosowania wody niezakwaszonej w większości ocenianych obiektów badań retardanty wzrostu zredukowały wysokość jęczmienia jarego w porównaniu do obiektu kontrolnego. W zależności od roku badań skrócenie źdźbeł jęczmienia jarego wyniosło odpowiednio od 0 do $5,9 \% \mathrm{w}$ roku 2010 oraz od 1,6 do $9,8 \%$ w roku 2011. Spośród preparatów najlepsze działanie retardacyjne w roku 2010 uzyskano po zastosowaniu etefonu, natomiast w roku 2011 - po trineksapaku etylu.

W wyniku obniżenia $\mathrm{pH}$ cieczy opryskowej stwierdzono istotny wzrost efektywności działania trineksapaku etylu w 2010 roku w porównaniu do obiektu badań, w którym zastosowano badany preparat w cieczy użytkowej o odczynie zbliżonym do obojętnego. Uzyskane relacje wystapiły jedynie w pierwszym roku badań. $\mathrm{W}$ następnym sezonie wegetacyjnym, niezależnie od $\mathrm{pH}$ cieczy opryskowej wysokość jęczmienia jarego kształtowała się na podobnym poziomie. W przypadku biologicznej oceny efektywności proheksadionu wapnia i chlorku chloromekwatu, w dwóch latach badań, otrzymano odmienne relacje. W pierwszym roku badań, w wariantach, w których zastosowano wyżej wymienione substancje czynne w cieczy opryskowej o odczynie kwaśnym odnotowano spadek efektywności działania, natomiast $\mathrm{w}$ drugim roku wystapiła tendencja do polepszenia ich biologicznej skuteczności. Na podstawie dwuletnich badań stwierdzono, że dodanie kwasu cytrynowego do cieczy opryskowej zawierającej etefon wpłynęło na pogorszenie efektywności jego działania.

Wyleganie jęczmienia jarego wystapiło jedynie w 2010 roku. Na podstawie uzyskanych danych zdecydowaną poprawę skuteczności działania stwierdzono jedynie w przypadku trineksapaku etylu stosowanego w warunkach obniżonego odczynu cieczy opryskowej. Wyleganie jęczmienia jarego w analizowanym obiekcie badań zmniejszyło się z 39,9 do 18,5\%. Działanie pozostałych retardantów było zbliżone, niezależnie od odczynu cieczy opryskowej i oscylowało w zakresie od 38,9 do 44,0\% (tab. 2).

W doświadczeniu oceniano ponadto wpływ badanych preparatów na strukturę plonu jęczmienia jarego (tab. 3). Obniżenie pH cieczy opryskowej zawierającej badane preparaty $\mathrm{w}$ większości ocenianych wariantów nie miało istotnego wpływu na obsadę roślin, masę tysiąca ziarniaków oraz liczbę nasion w kłosie. W niektórych wariantach badań uzyskano nieznaczne wahania masy tysiąca ziarniaków oraz ich liczby w kłosie. Zdaniem wielu 
autorów zastosowane preparaty wpływają na zwiększenie plonowania zbóż, w tym na poszczególne elementy struktury plonu: obsadę źdźbeł kłosonośnych, liczbę ziaren w kłosie oraz masę tysiąca ziarniaków (Starczewski i wsp. 2002). W odniesieniu do dwóch pierwszych elementów struktury plonu większość opinii jest zgodnych. Najwięcej rozbieżności pojawia się odnośnie wpływu retardantów na masę tysiąca ziarniaków (Giltrap i Garstang 1991; Woolley 1991; Starczewski i wsp. 2002).

W obiektach badań, w których zastosowano retardanty wzrostu, uzyskano przyrost plonowania rośliny uprawnej w porównaniu do obiektu kontrolnego. Analizując wpływ odczynu cieczy opryskowej oraz retardanta wzrostu na plonowanie jęczmienia jarego w dwóch latach badań odnotowano zróżnicowane relacje. W pierwszym roku, w obiektach badań, w których stosowano proheksadion wapnia, chlorek chloromekwatu oraz etefon w warunkach obniżonego $\mathrm{pH}$ cieczy opryskowej, stwierdzono nieistotne obniżenie plonowania. W drugim roku, w większości ocenianych wariantów badań, uzyskano istotną zwyżkę plonowania jęczmienia jarego. Odmienne relacje stwierdzono w przypadku trineksapaku etylu. Obniżenie $\mathrm{pH}$ cieczy opryskowej, a tym samym ograniczenie wylegania wpłynęło na polepszenie plonowania rośliny uprawnej. W obydwu latach badań nie stwierdzono fitotoksycznego oddziaływania badanych preparatów na jęczmień jary odmiany Justina.

\section{Wnioski / Conclusions}

1. W obydwu latach badań największe skrócenie długości źdźbła uzyskano stosując preparat Cerone 480 SL.

2. Odczyn cieczy opryskowej nie miał istotnego wpływu na efektywność działania następujących regulatorów wzrostu: proheksadionu wapnia, chlorku chloromekwatu oraz etefonu.

3. W wyniku zakwaszenia cieczy opryskowej zawierającej trineksapak etylu stwierdzono tendencję do polepszenia efektywności działania retardanta wzrostu - redukcja wysokości jęczmienia oraz obniżenie wylegania.

4. Badane retardanty wzrostu niezależnie od odczynu cieczy opryskowej nie miały fitotoksycznego wpływu na rośliny jęczmienia jarego odmiany Justina.

5. Obniżenie odczynu cieczy opryskowej zawierającej retardanty wzrostu - proheksadion wapnia, chlorek chloromekwatu oraz etefon nie miało istotnego wpływu na następujące elementy plonowania (obsadę roślin, MTZ, liczbę ziarniaków w kłosie). W wyniku obniżenia $\mathrm{pH}$ cieczy opryskowej zawierającej trineksapak etylu uzyskano przyrost plonowania jęczmienia jarego w porównaniu do obiektu badań, w którym stosowano preparat w odczynie cieczy opryskowej zbliżonym do obojętnego.

\section{Literatura / References}

Giltrap N.J., Garstang J.R. 1991. Effect of PGRS and nitrogen rate on grain yield and quality of Marinka winter barley. The BCPC - Weeds 7C-10: 987-994.

Green J.M., Cahill W.R. 2003. Enhancing the biological activity of nicosulfuron with pH adjusters. Weed Technol. 17: 338-345.

Kelbert A.J., Spaner D., Briggs K.G., King J.R. 2004. The association of culm anatomy with lodging susceptibility in modern spring wheat genotypes. Euphytica 136: 211-221.

Łęgowiak Z., Wysmułek A. 2000. Stosowanie regulatorów wzrostu w zbożach. [Plant growth regulators in cereals]. Prog. Plant Prot./ Post. Ochr. Roślin 40 (2): 932-934.

Toboła P., Muśnicki Cz. 1998. Wpływ etefonu na wzrost, rozwój i plonowanie słonecznika oleistego. Materiały 35. Sesji Nauk. Inst. Ochr. Roślin, cz. 1: 338-341.

Tripathi S.C., Sayre K.D., Kaul J.N., Narang R.S. 2004. Lodging behavior and yield potential of spring wheat (Triticum aestrivum L.) effects of ethephon and genotypes. Field Crops Res. 87: 207-220.

Starczewski J., Bombik A., Dopka D. 2002. Plonowanie i struktura plonu pszenżyta ozimego w zależności od nawożenia azotem i wybranych retardantów. Folia Univ. Agric. Stetin. Agricultura 228 (91): 147-154.

Sterry J.R. 1980. Ethephon as a plant growth regulator on winter barley: results and present status in Europe. The BCPC - Weeds: 687-692.

Szeleźniak E. 2005. Wpływ związków mineralnych i organicznych modyfikujących pH cieczy opryskowej na skuteczność działania tralkoksydymu. Pam. Puł. 140: 297-309.

Woolley E.W. 1991. Recent experience of timing of growth regulators on winter wheat. The BCPC - Weeds 7C-10: 981-986.

Woźnica Z., Nalewaja J.D., Messershmith G., Milkowski P. 2003. Quinclorac efficasy as effected by adjuvants and spray carrier water. Weed Technol. 17: 582-588. 